\title{
The expression of long non-coding RNA HOTAIR in advanced hepatocellular carcinoma and its prognostic correlation with sunitinib therapy
}

\author{
Chenyang Han ${ }^{1}$, Yi Yang ${ }^{1}$, Li Guo², Qiaobing Guan³, Shuiliang Ruan³
}

\begin{abstract}
${ }^{1}$ Department of Pharmacy, The Second Affiliated Hospital of Jiaxing University, Jiaxing, China

${ }^{2}$ Centre Laboratory, The Second Affiliated Hospital of Jiaxing University, Jiaxing, China ${ }^{3}$ Department of Gastroenterology, The Second Affiliated Hospital of Jiaxing University, Jiaxing, China
\end{abstract}

Submitted: 22 September 2018; Accepted: 3 December 2018

Online publication: 18 March 2021

Arch Med Sci 2022; 18 (1): 71-78

DOI: https://doi.org/10.5114/aoms/100480

Copyright $\odot 2021$ Termedia \& Banach

\section{Abstract}

Introduction: The study was designed to assess the expression of long non-coding RNA HOTAIR (IncRNA HOTAIR) in tissues and peripheral blood of patients with advanced hepatocellular carcinoma (HCC). In addition, we also investigated the prognostic correlation between the expression level of IncRNA HOTAIR in tumour tissues and peripheral blood of patients with advanced HCC and sunitinib monotherapy.

Material and methods: A total of 60 patients with advanced HCC who received sunitinib monotherapy and another 60 healthy individuals who were examined at the physical examination centre during the same period were included in the study. Real-time quantitative PCR (RT-QPCR) was used to determine the relative expression of IncRNA HOTAIR in tumour tissue, adjacent tissue, and peripheral blood of HCC patients as well as peripheral blood of healthy controls. Moreover, the clinicopathological information, overall survival (OS), and progression-free survival (PFS) were collected, followed by correlation analysis with IncRNA HOTAIR expression.

Results: The expression of IncRNA HOTAIR was significantly higher in tumour tissues compared to that in adjacent tissues $(t=9.03, p<0.001)$. The expression of IncRNA HOTAIR in peripheral blood of HCC patients was higher than that in healthy controls $(t=8.04, p<0.001)$. There was a correlation between the expression of IncRNA HOTAIR in tumour tissue and peripheral blood in HCC patients $(r=0.638, p<0.001)$. Patients with low IncRNA HOTAIR expression in tumour tissues harboured significantly longer OS (13.4 vs. 9.5, $p<0.001)$ and PFS (8.4 vs. 6.2, $p<0.001)$ compared to those with high expression. Consistently, patients with low IncRNA HOTAIR expression in peripheral blood had significantly prolonged OS (12.8 vs. 9.1, $p<0.001)$ and PFS (8.9 vs. $6.4, p<0.001)$ compared to those with high expression. Patients with low expression both in tumour tissue and peripheral blood had prolonged OS (14.3 vs. 8.8, $p<0.001)$ and PFS (10.6 vs. $6.0, p<0.001)$ compared to the rest of the patients. Cox regression analysis indicated that the expression level of IncRNA HOTAIR in tumour tissue and peripheral blood was an independent predictive factor of OS and PFS in patients with advanced HCC treated by sunitinib.

Conclusions: The expression of IncRNA HOTAIR was up-regulated in tumour tissue and peripheral blood in patients with advanced HCC. In addition, the expression level of IncRNA HOTAIR was one of the indicators predicting the effectiveness of sunitinib therapy.

Key words: IncRNA HOTAIR, sunitinib, hepatocellular carcinoma, real-time quantitative polymerase chain reaction.

\author{
Corresponding author: \\ Shuiliang Ruan \\ Department \\ of Gastroenterology \\ The Second Affiliated \\ Hospital of \\ Jiaxing University \\ Jiaxing, China \\ E-mail: ruanguan20@126. \\ com
}




\section{Introduction}

Primary hepatocellular carcinoma (HCC) is a highly malignant tumour with a high incidence in Asian countries. The pathogenesis of HCC is complicated, and multiple signal transductions are involved in the carcinogenesis and tumour progression [1]. However, HCC is not easily detected in the early stage. A considerable number of patients are already burdened with moderate to advanced stages after diagnosis, and the treatment is extremely difficult. Only $10 \%$ to $30 \%$ of HCC patients can undergo surgery in the clinic. Transcatheter arterial chemoembolization (TACE), radiofrequency ablation, and other treatments are generally performed in patients who cannot undergo surgery, while chemotherapy and targeted therapy are conducted in the majority of patients $[2,3]$. At present, the first choice of chemotherapeutic drugs in HCC treatment is cytotoxic drugs such as gemcitabine and fluorouracil, which are accompanied with heavy side effects and lack of reproducibility [4]. Therefore, targeted therapy is gradually being promoted at present.

Sunitinib is a novel oral small molecule, multi-targeted tyrosine kinase inhibitor. It has been proven that it harbours anti-tumour angiogenesis and anti-tumour activity. Its mechanism is mainly via inhibition of members of the receptor tyrosine kinase (RTK) family, including vascular endothelial growth factor receptor (VEGFR-1/2), platelet-derived growth factor receptor (FDGFR- $\alpha / \beta)$, foetal liver tyrosine kinase receptor (FLT3), and colony-stimulating factor 1 (CSF-1), etc. [5]. Clinical trials have verified that sunitinib has significant clinical efficacy on gastrointestinal stromal tumours (GIST), metastatic renal cell carcinoma, and HCC, which can prolong overall survival (OS) and progression-free survival (PFS) [6]. However, similar with other targeted drugs, there are obvious individual differences of sunitinib efficacy, with unrevealed reasons for this individualized difference.

Long non-coding RNA (IncRNA) is a member of the non-coding RNA (nc RNA) family. More and more studies have demonstrated that IncRNA is closely associated with tumour progression and chemotherapeutic resistance, etc. [7]. The IncRNA HOTAIR study has shown that it is highly expressed in multiple malignant tumours, which can be used as a prognostic marker of breast cancer and be utilized to predict the prognosis of HCC transplantation. Additionally, other studies have shown that IncRNA HOTAIR is correlated with drug resistance of cisplatin, trastuzumab, etc. Therefore, in this study, from a clinical perspective, we assessed the expression of IncRNA HOTAIR in advanced HCC patients, and we investigated the correlation of IncRNA HOTAIR expression with prognosis follow- ing sunitinib therapy, aiming to provide reference and support for personalized medicine in clinical practice.

\section{Material and methods}

\section{Origins of cases}

Of the 60 patients enrolled in this study, all were diagnosed with advanced HCC (TNM stage III and IV). All patients did not receive any anti-tumour therapy when they were enrolled, including chemotherapy, radiotherapy, or biological therapy. Patients were confirmed by medical history, signs, laboratory examinations, and imaging examinations. These patients were unable to undergo surgical resection or local treatment. The histological tissue obtained by needle biopsy was confirmed as stage III and IV according to the International Union Against Cancer and the American Joint Committee on Cancer TNM staging classification (seventh edition). Among the 60 patients, there were 35 males and 25 females. Before the treatment, the ECOG score of the patients was 0-2, with $B$ or $C$ of Barcelona staging and $A$ or $B$ of Child-Pugh liver function.

Sixty patients were treated with sunitinib monotherapy. All patients were treated with sunitinib malate (Pfizer). In brief, sunitinib was orally administered at a dose of $37.5 \mathrm{mg}$ once daily for 4 consecutive weeks. In the case of drug-related dose-limiting side effects, treatment can be reduced or discontinued, according to the patient's tolerance, until the emergence of disease progression or death. The dose reduction was performed at a gradient dose of $12.5 \mathrm{mg}$ based on the type and severity of adverse reactions. In the case of 2 consecutive adverse reactions of Grade 3, the drug dose could be reduced by 1 level. In the case of Grade 4 adverse reactions, sunitinib administration was ceased, while the patient was re-administered with sunitinib by decreasing by 1 dose level after recovery. The minimum dose was $12.5 \mathrm{mg}$ in all patients, and in the case of another intolerance, they would be permanently discontinued. All patients signed written informed consent before receiving treatment. This study was approved by the Ethics Committee of the Second Affiliated Hospital of Jiaxing University.

\section{The extraction of total RNA from peripheral blood and tumour tissue of patients}

Peripheral blood and tumour tissue was obtained from 50 patients before treatment. The extraction of total RNA from peripheral blood was as follows. After the patient was fasted for $12 \mathrm{~h}$, $5 \mathrm{ml}$ of peripheral blood was collected at the elbow, which was placed in a heparin anticoagulant 
tube. After dilution with the same dose of PBS, mixing by pipetting at room temperature, a $1 / 2$ diluted volume of lymphocyte separation solution (Histopaque-1077, Sigma, USA) was added to the centrifuge tube, added slowly along the wall of the tube, followed by centrifugation at $3000 \mathrm{rpm}$ for $30 \mathrm{~min}$ to obtain peripheral blood mononuclear cells (PBMCS). The EZNA Blood RNA Mini Kit (Omega, US) was used to extract RNA from PBMCs. Total RNA was extracted and stored at $-80^{\circ} \mathrm{C}$, and CDNA was synthesized within 1 week and stored at $-20^{\circ} \mathrm{C}$. The extraction of RNA from tumour tissue was as follows. Briefly, a small amount of liquid nitrogen was added to the mortar, and we waited until the liquid nitrogen volatilized to completely pre-cool the mortar. An appropriate amount of liquid nitrogen was added, and tumour tissue was subsequently added to grind it, followed by the addition of $1 \mathrm{ml}$ of TRIzol after powdering. After the tissue was completely dissolved, the homogenate was transferred to an EP tube. Afterwards, an Invitrogen TRIzol kit (Invitrogen, US) was used to extract RNA, which was stored at $-80^{\circ} \mathrm{C}$, and $\mathrm{CDNA}$ was synthesized within 1 week and stored at $-20^{\circ} \mathrm{C}$.

\section{Real-time quantitative PCR (RT-qPCR)}

Total RNA was reverse-transcribed using the PrimeScript $^{\text {TM }}$ RT reagent kit with gDNA Eraser kit (Takara, China). In the reaction system, $1 \mu \mathrm{g}$ of RNA was contained in per $20 \mu \mathrm{l}$ of the system. The reverse transcription was performed as follows: $7 \mu$ of $60 \mathrm{ng} / \mu \mathrm{l}$ RNA, $2 \mu$ l of $5 \times$ gDNA Eraser buffer, and $1 \mu \mathrm{l}$ of gDNA Eraser were mixed and reacted for $1 \mathrm{~min}$ at $45^{\circ} \mathrm{C}$, followed by the addition of $4 \mu$ l of $5 \times$ PrimeScript Enzyme Buffer, $1 \mu \mathrm{l}$ of PrimeScript Enzyme, $1 \mu$ l of PrimeScript RT Mix, and $4 \mu \mathrm{l}$ of nuclease-free $\mathrm{H}_{2} \mathrm{O}$, which were mixed and incubated at $37^{\circ} \mathrm{C}$ for 15 min to obtain CDNAs. The synthesized cDNA was amplified using SYBR Premix Ex Taq II reagent (Takara, China) in a 10$\mu l$ reaction system. The reagents and procedures of qPCR were as follows: $5 \mu$ of $2 \times S Y B R \circledast$ Premix Ex TaqTM and $0.2 \mu \mathrm{l}$ Primer Forward $(10 \mathrm{pmol} / \mu \mathrm{l})$, $0.2 \mu \mathrm{l}$ Primer Reverse $(10 \mathrm{pmol} / \mu \mathrm{l}), 0.2 \mu \mathrm{l}$ ROX Dye II, and $2.4 \mu \mathrm{l}$ Nuclease-free $\mathrm{H}_{2} \mathrm{O}$ were mixed and amplified using $A B I$ step one. The reaction conditions were as follows: $95^{\circ} \mathrm{C}$ for $2 \mathrm{~min}$, 40 cycles of $15 \mathrm{~s}$ at $95^{\circ} \mathrm{C}$ and $30 \mathrm{~s}$ at $58^{\circ} \mathrm{C}$; the fluorescence was collected at $58^{\circ} \mathrm{C}$. The dissolution temperature was gradually increased from $58^{\circ} \mathrm{C}$ to $95^{\circ} \mathrm{C}$, and fluorescence was collected by every $0.5^{\circ} \mathrm{C}$ increase. The IncRNA HOTAIR forward primer: 5'-GCCTGAACTTCCTCCTGCTATT-3', the reverse primer 5'-ACAC-AAAGTGCATACCTACCCA-3' (329 bp in length). The internal reference $\beta$-actin forward primer 5'-AAGAGAGGCATCCTCACCCT-3', the reverse primer 5'-TACATGGCTGGGGTGTTGAA-3' (216 bp in length).

\section{Statistical analysis}

SPSS19.0 software was used for statistical analysis. The measurement data were compared by t-test, analysis of variance and Mann-Whitney $U$ test. The survival analysis was conducted by Kaplan-Meier method, followed by log-rank test for the comparison between groups. Cox regression analysis was used for univariate and multivariate analyses. $P<0.05$ was considered as statistical significance.

\section{Results}

\section{Basic information of the patients}

A total of 60 patients were enrolled in this study, who were admitted and diagnosed with advanced-stage HCC at the Second Affiliated Hospital of Jiaxing University from January 2015 to December 2016. Among them, 35 were male and 25 were female, 38 were in stage III, and 22 were in stage IV. The median OS was 10.4 months (range: 6.5-18.7 months), and the median PFS was 6.8 (range: 3.8-11.6). The basic information of patients is shown in Table $\mathrm{I}$.

The expression level of IncRNA HOTAIR in tumour tissue and peripheral blood of patients

The average expression level of IncRNA HOTAIR in tumour tissues of HCC patients was 5.07 (range:

Table I. Basic information of patients

\begin{tabular}{|c|c|c|}
\hline Factors & $\begin{array}{l}\text { Number } \\
\text { of cases }\end{array}$ & Percentage (\%) \\
\hline \multicolumn{3}{|l|}{ Age [years]: } \\
\hline Median (range) & $64(42-78)$ & \\
\hline \multicolumn{3}{|l|}{ Gender: } \\
\hline Male & 35 & 58 \\
\hline Female & 25 & 42 \\
\hline \multicolumn{3}{|l|}{ Alcohol drinking: } \\
\hline Yes & 31 & 52 \\
\hline No & 29 & 48 \\
\hline \multicolumn{3}{|l|}{ Stage: } \\
\hline III & 38 & 63 \\
\hline IV & 22 & 37 \\
\hline \multicolumn{3}{|l|}{ Hepatocirrhosis: } \\
\hline Yes & 20 & 33 \\
\hline No & 40 & 67 \\
\hline \multicolumn{3}{|l|}{ Metastasis sites: } \\
\hline Lymph node & 25 & 41 \\
\hline Lung & 15 & 25 \\
\hline Bone & 10 & 17 \\
\hline Others & 10 & 17 \\
\hline
\end{tabular}


A

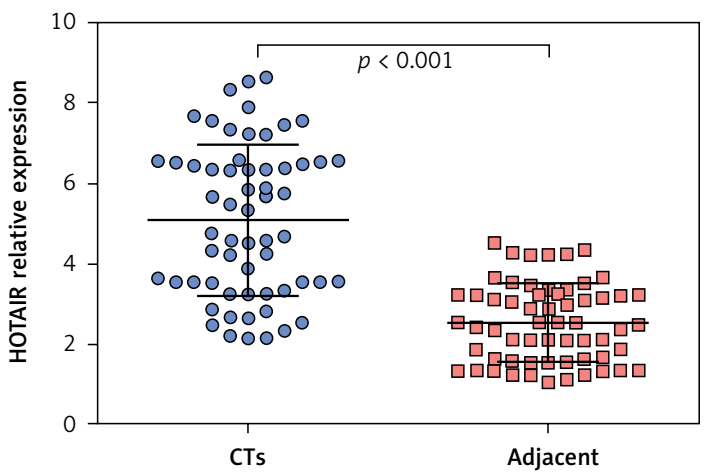

B

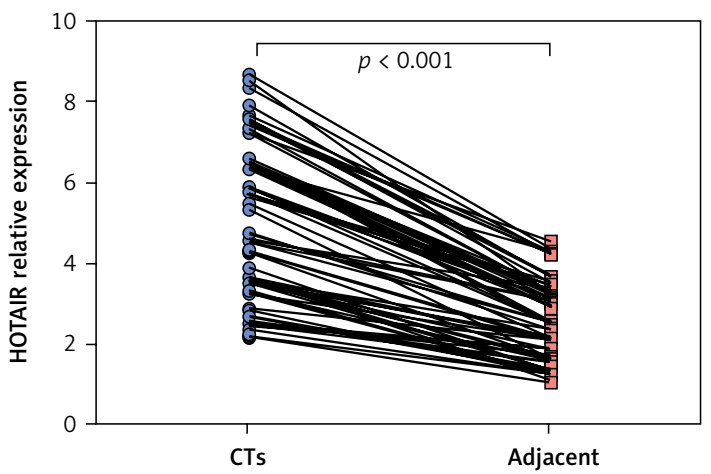

Figure 1. The expression level of IncRNA HOTAIR in tumour tissue and adjacent tissue $(n=60)$ CTs - cancer tissue, adjacent - adjacent tissue.

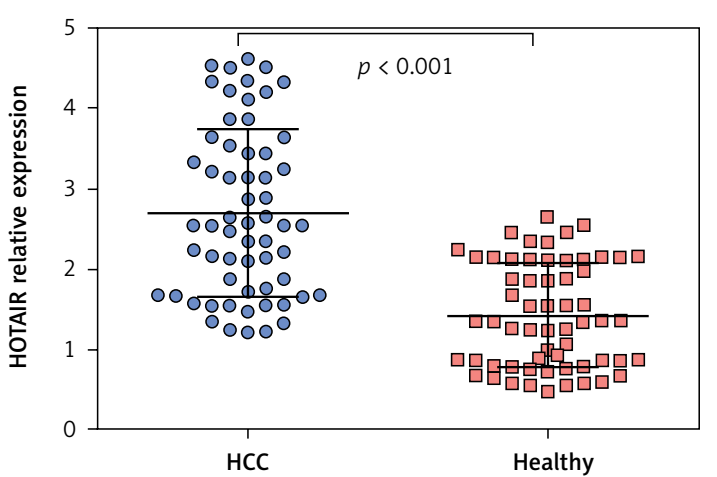

Figure 2. The expression level of IncRNA HOTAIR in peripheral blood of hepatocellular carcinoma (HCC) $(n=60)$

HCC - hepatocellular carcinoma patients, healthy healthy people.

2.14-8.65, mean: $5.07 \pm 1.74$ ), and the average expression level of IncRNA HOTAIR in adjacent tissues was 2.53 (range: 4.52-1.04, mean: 2.53 \pm 0.89 ). The level of IncRNA HOTAIR in tumour tissues was significantly higher than that in adjacent tissues $(t=9.03, p<0.001)$, as shown in Figures 1 $A$ and $B$. The average expression level of IncRNA HOTAIR in peripheral blood of HCC patients was 2.69 (range: 4.62-1.21, mean: $2.69 \pm 0.89$ ), and the average expression level of IncRNA HOTAIR in peripheral blood of healthy individuals was 1.41 (range: $2.64-0.67$, mean: $1.41 \pm 0.48$ ), which were statistically different $(t=8.04, p<0.001)$. The results are shown in Figure 2. The expression level of IncRNA HOTAIR in tumour tissue and peripheral blood of HCC patients was correlated $(r=0.638$, $p<0.001)$

The correlation of the expression level of IncRNA HOTAIR with clinicopathological characteristics

The median of IncRNA HOTAIR expression in tumour tissues was 5.1, and the median of InCRNA HOTAIR expression in peripheral blood was
2.7. The medians were used as cut-offs, and patients were divided into a high-expression group (High) and a low-expression group (Low). The Mann-Whitney $U$ test revealed that the expression level of IncRNA HOTAIR was not correlated with clinicopathological characteristics, including age ( $p=0.73,0.93)$, gender $(p=0.38,0.71)$, drinking history $(p=0.31,0.31)$, physical status ( $p=$ $0.81,0.78)$, tumour stage $(p=0.10,0.23)$, and cirrhosis history $(p=0.69,0.46)$ (shown in Table II).

The correlation of OS and PFS with the expression level of IncRNA HOTAIR in tumour tissue and peripheral blood

The median OS of patients with low and high IncRNA HOTAIR expression in tumour tissue was 13.4 vs. 9.5 (log-rank 17.9, $p<0.001$, Figure 3 A). The median OS of patients with low and high expression of IncRNA HOTAIR in peripheral blood was 12.8 vs. 9.1 (log-rank 16.3, $p<0.001$, Figure 3 B). The median PFS of patients with low and high IncRNA HOTAIR expression in tumour tissues was 8.4 vs. 6.2 (log-rank 19.7, $p<0.001$, Figure 3 C). The median PFS in patients with low and high IncRNA HOTAIR expression in peripheral blood was 8.9 vs. 6.4 (log-rank 18.3, $p<0.001$, Figure 3 D). The median OS of patients with low expression of IncRNA in both tumours and peripheral blood and the rest of the patients was 14.3 vs. 8.8 (log-rank 21.8, $p<0.001$, Figure $3 \mathrm{E}$ ). The median PFS of patients with low expression of IncRNA in both tumours and peripheral blood and the rest patients was 10.6 vs. 6.0 (log-rank 20.4, $p<0.001$, Figure 3 F). The results were shown in Figure 3.

\section{Correlation between OS and clinicopathological characteristics}

The clinical stage and physical status of HCC patients were correlated with their OS (log-rank: $6.571,5.351, p=0.013,0.018)$. COX regression analysis demonstrated that patients with low ex- 
Table II. The correlation between IncRNA HOTAIR expression and the clinicopathological characteristics of patients $(n \%)$

\begin{tabular}{|c|c|c|c|c|}
\hline \multirow{2}{*}{$\begin{array}{l}\text { Clinical and pathological } \\
\text { factors }\end{array}$} & \multicolumn{2}{|c|}{ IncRNA HOTAIR in tumour } & \multicolumn{2}{|c|}{ IncRNA HOTAIR in peripheral blood } \\
\hline & Low $(n=30)$ & High $(n=30)$ & Low $(n=30)$ & High $(n=30)$ \\
\hline \multicolumn{5}{|l|}{ Age [years]: } \\
\hline$\leq 60$ & $13(43)$ & $15(50)$ & $14(47)$ & $14(47)$ \\
\hline$>60$ & $17(57)$ & $15(50)$ & $16(53)$ & $16(53)$ \\
\hline \multicolumn{5}{|l|}{ Gender: } \\
\hline Male & $16(53)$ & $19(63)$ & $17(57)$ & $18(60)$ \\
\hline Female & $14(47)$ & $11(37)$ & $13(43)$ & $12(40)$ \\
\hline \multicolumn{5}{|l|}{ Alcohol drinking: } \\
\hline Yes & $17(57)$ & $14(47)$ & $17(57)$ & $14(47)$ \\
\hline No & $13(43)$ & $16(53)$ & $13(43)$ & $16(53)$ \\
\hline \multicolumn{5}{|l|}{ Performance status: } \\
\hline 0 & $14(47)$ & $15(50)$ & $15(50)$ & $14(47)$ \\
\hline 1 & $16(53)$ & $15(50)$ & $15(50)$ & $16(53)$ \\
\hline \multicolumn{5}{|l|}{ Hepatocirrhosis: } \\
\hline Yes & $9(30)$ & $11(37)$ & $8(27)$ & $12(40)$ \\
\hline No & $21(70)$ & $19(63)$ & $22(73)$ & $18(60)$ \\
\hline \multicolumn{5}{|l|}{ Tumour stage: } \\
\hline III & $21(70)$ & $17(57)$ & $20(67)$ & $18(60)$ \\
\hline IV & $9(30)$ & $13(43)$ & $10(33)$ & $12(40)$ \\
\hline
\end{tabular}

No significant differences were observed between the levels of gene expression as dichotomous variable (low vs. high) across clinical and pathological factors using the Mann-Whitney $U$ test $(p>0.05)$.

pression of IncRNA HOTAIR in tumour tissues or peripheral blood had longer OS $(\mathrm{HR}=4.035,4.135$, $p=0.04$, and 0.031). Patients with low expression of IncRNA HOTAIR in both tumour tissue and peripheral blood had further prolonged OS $(H R=$ 9.873, $p=0.001)$. The results are shown in Table III.

\section{Correlation between PFS and clinicopathological characteristics}

The clinical stage and physical status of patients were correlated with their PFS (log-rank: 7.685, $6.354, p=0.031,0.038)$. COX regression analysis revealed that patients with low expression of InCRNA HOTAIR in tissues or peripheral blood had longer PFS (HR $=3.852,3.168, p=0.025,0.026)$. Patients with low expression of IncRNA HOTAIR in both tumour tissue and peripheral blood had prolonged PFS $(H R=9.341, p=0.001)$. The results are shown in Table IV.

\section{Incidence of adverse reactions during sunitinib treatment}

Digestive tract adverse reactions include the following: nausea, vomiting, diarrhoea, indigestion, constipation, etc. A total of 12 patients developed such adverse reactions, all of which were grade I, with an incidence of $20 \%$. Two patients had abnormal liver function and recovered after drug reduction. One patient developed a rash and resumed after withdrawal, and no obvious adverse reactions were found in other patients. The incidence of gastrointestinal adverse reactions of sunitinib is the highest, but the degree is low, and patients can tolerate it.

\section{Discussion}

Primary liver cancer is a common malignancy and is particularly prevalent in Southeast Asian countries. HCC is one type of primary liver cancer with relatively high prevalence. In particular, a considerable proportion of patients are already in advanced stages when they are diagnosed. For those patients, treatment is relatively tough, and the prognosis is relatively poor. At present, great attention has been paid to multi-kinase inhibitor targeted drugs as therapeutic approaches to HCC. Currently, targeted drugs for HCC include somatonin, sunitinib, etc. [8].

Sunitinib is a multi-kinase small molecule compound that inhibits tyrosine kinase targets such as VEGFR (VEGFR1-3) and PDGFR. In a Phase II, multicentre, European/Asian clinical trial in 2006, the median OS was 44 weeks and the TPP was 21 weeks, in patients undergoing sunitinib monotherapy. According to Response Evaluation Criteria in Solid Tumours (RECIST), over $30 \%$ of tumours underwent necrosis after 1-1.5 months 
A

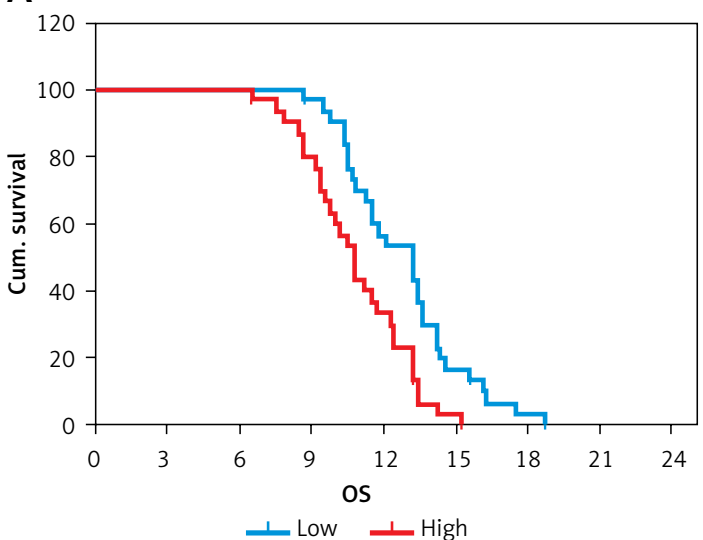

C

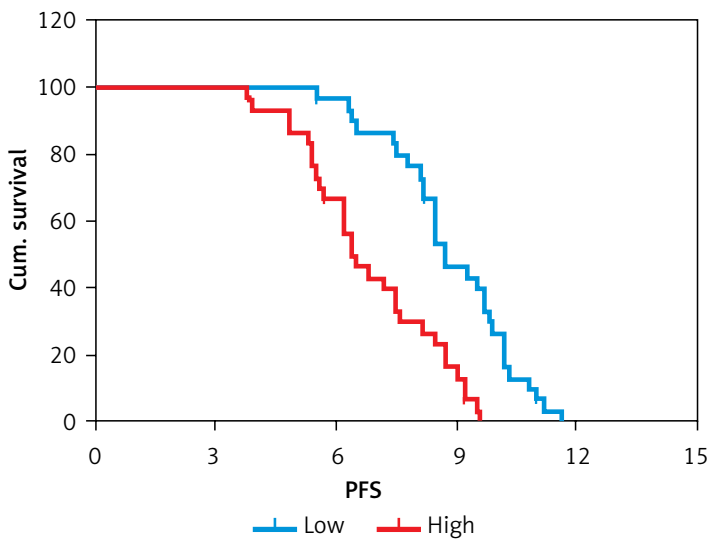

E

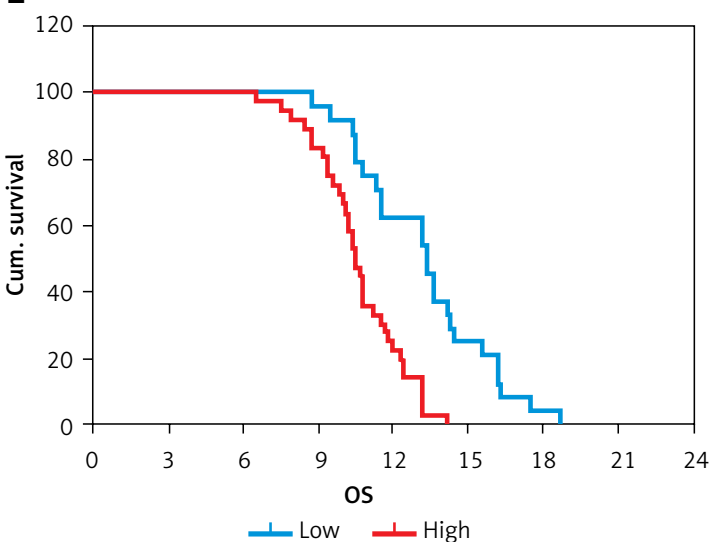

B

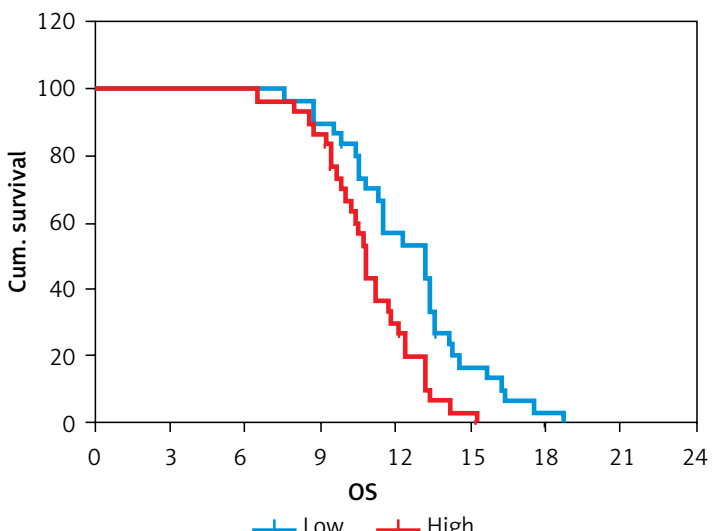

D

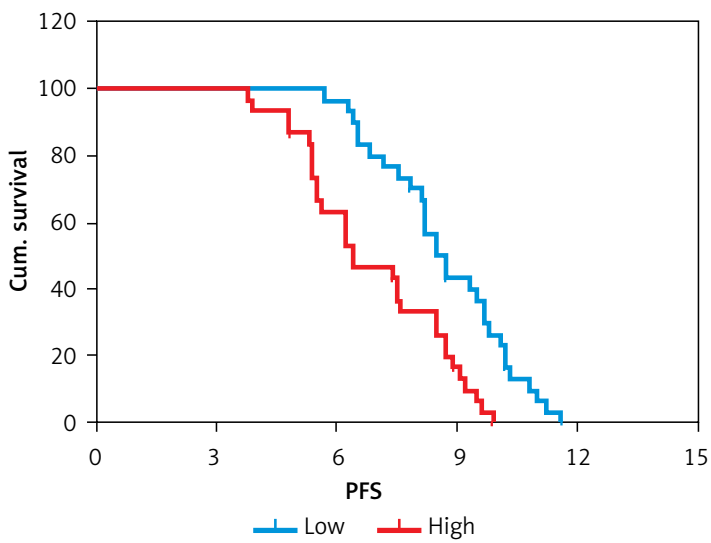

$\mathrm{F}$

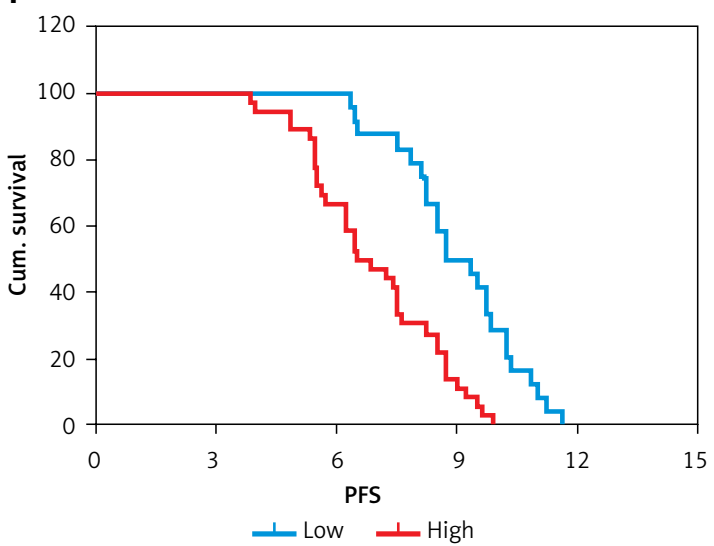

Figure 3. The correlation of IncRNA HOTAIR expression with overall survival (OS) and progression-free survival (PFS) High - patients with high expression of InCRNA HOTAIR, Low - patients with low expression of IncRNA HOTAIR.

of treatment, indicating that sunitinib exerted an anti-hepatocarcinogenic effect [9]. The second phase II clinical trial showed [10] that of the 45 patients with advanced HCC treated with $37.5 \mathrm{mg} /$ day sunitinib, 15 patients were still alive and had no significant progress after 12 weeks. The median TPP was 3.2 months, and the median OS was 9.3 months, which was consistent with our findings (median OS: 10.4 months, ranging from 6.5 to 18.7 months, median PFS: 6.8, ranging from 3.8 to 11.6 months), suggesting that sunitinib has little difference in overall efficacy in HCC therapy, and consistency with previous studies. However, in previous studies, we found that the therapeutic efficacy of sunitinib in HCC patients was quite different. In addition, there is no study concerning the efficacy prediction and evaluation. We speculate that it might be related to HCC progression, primary resistance of patients, acquired drug resistance, and adaptive drug resistance. 
Table III. The correlation between OS and clinicopathological characteristics

\begin{tabular}{|c|c|c|c|c|c|c|}
\hline \multirow{2}{*}{$\begin{array}{l}\text { Clinical and } \\
\text { pathological } \\
\text { factors }\end{array}$} & \multirow{2}{*}{$\begin{array}{l}\text { Number } \\
\text { of patients }\end{array}$} & \multirow{2}{*}{$\begin{array}{l}\text { Median OS } \\
\text { [month] }\end{array}$} & \multicolumn{2}{|c|}{ Univariate analysis } & \multicolumn{2}{|c|}{ Multivariate analysis } \\
\hline & & & Log-rank & $P$-value & HR $(95 \% \mathrm{Cl})$ & $P$-value \\
\hline \multicolumn{7}{|l|}{ Stage: } \\
\hline III & 38 & $13.7(8.6-18.7)$ & \multirow[t]{2}{*}{6.571} & \multirow[t]{2}{*}{0.013} & \multirow[t]{2}{*}{$2.134(0.832-3.938)$} & \multirow[t]{2}{*}{0.083} \\
\hline IV & 22 & $10.1(6.5-15.2)$ & & & & \\
\hline \multicolumn{7}{|l|}{$\begin{array}{l}\text { Performance } \\
\text { status: }\end{array}$} \\
\hline 0 & 29 & $13.6(8.9-18.7)$ & \multirow[t]{2}{*}{5.351} & \multirow[t]{2}{*}{0.018} & \multirow[t]{2}{*}{$2.865(0.911-4.325)$} & \multirow[t]{2}{*}{0.024} \\
\hline 1 & 31 & $10.2(6.5-15.0)$ & & & & \\
\hline \multicolumn{7}{|l|}{$\begin{array}{l}\text { In peripheral } \\
\text { blood: }\end{array}$} \\
\hline HOTAIR Low & 30 & $12.8(7.8-18.7)$ & \multirow[t]{2}{*}{6.857} & \multirow[t]{2}{*}{0.016} & \multirow[t]{2}{*}{$4.035(1.731-5.854)$} & \multirow[t]{2}{*}{0.040} \\
\hline HOTAIR High & 30 & $9.1(6.5-12.6)$ & & & & \\
\hline \multicolumn{7}{|l|}{ In tumour tissue: } \\
\hline HOTAIR Low & 30 & $13.4(8.9-18.7)$ & \multirow[t]{2}{*}{6.147} & \multirow[t]{2}{*}{0.012} & 4.135 & \multirow[t]{2}{*}{0.031} \\
\hline HOTAIR High & 30 & $9.5(6.5-13.0)$ & & & 1.832-6.154) & \\
\hline \multicolumn{7}{|c|}{$\begin{array}{l}\text { In peripheral blood } \\
\text { and tumour tissue: }\end{array}$} \\
\hline Both low & 24 & $14.3(10.0-18.7)$ & 10.87 & 0.001 & $9.873(2.867-21.368)$ & 0.001 \\
\hline
\end{tabular}

Table IV. The correlation between PFS and clinicopathological characteristics

\begin{tabular}{|c|c|c|c|c|c|c|}
\hline \multirow{2}{*}{$\begin{array}{l}\text { Clinical and } \\
\text { pathological } \\
\text { factors }\end{array}$} & \multirow{2}{*}{$\begin{array}{l}\text { Number of } \\
\text { patients }\end{array}$} & \multirow{2}{*}{$\begin{array}{l}\text { Median OS } \\
\text { [month] }\end{array}$} & \multicolumn{2}{|c|}{ Univariate analysis } & \multicolumn{2}{|c|}{ Multivariate analysis } \\
\hline & & & Log-rank & $P$-value & HR $(95 \% \mathrm{Cl})$ & $P$-value \\
\hline \multicolumn{7}{|l|}{ Stage: } \\
\hline III & 38 & $9.0(6.3-11.6)$ & 7.685 & 0.031 & $3.120(1.132-11.240)$ & 0.024 \\
\hline IV & 22 & $6.5(3.8-9.5)$ & & & & \\
\hline \multicolumn{7}{|l|}{$\begin{array}{l}\text { Performance } \\
\text { status: }\end{array}$} \\
\hline 0 & 29 & $9.2(6.5-11.6)$ & 6.354 & 0.038 & $3.138(1.854-9.543)$ & 0.031 \\
\hline 1 & 31 & $6.1(3.8-9.2)$ & & & & \\
\hline \multicolumn{7}{|l|}{$\begin{array}{l}\text { In peripheral } \\
\text { blood: }\end{array}$} \\
\hline HOTAIR LOW & 30 & $8.9(6.1-11.6)$ & 5.864 & 0.032 & $3.852(1.358-13.210)$ & 0.025 \\
\hline HOTAIR High & 30 & $6.4(3.8-9.4)$ & & & & \\
\hline \multicolumn{7}{|l|}{ In tumour tissue: } \\
\hline HOTAIR Low & 30 & $8.4(5.4-11.6)$ & 8.358 & 0.013 & $3.168(1.281-12.854)$ & 0.026 \\
\hline HOTAIR High & 30 & $6.2(3.8-8.8)$ & & & & \\
\hline \multicolumn{7}{|l|}{$\begin{array}{l}\text { In peripheral } \\
\text { blood and tumour } \\
\text { tissue: }\end{array}$} \\
\hline Both low & 24 & $10.6(9.2-11.6)$ & 11.563 & 0.001 & 9.341 (3.152-21.574) & 0.001 \\
\hline
\end{tabular}

In the study of tumours, there have been extensive studies concerning non-coding RNA as a marker of tumour prognosis, especially IncRNA. InCRNA HOTAIR is relatively mature in the study of tumours. The present reports demonstrate that the expression of IncRNA HOTAIR is high in a variety of tumours. Gupta et al. have reported that InCRNA HOTAIR is an important prognostic indica- tor in primary breast cancer, and IncRNA HOTAIR can regulate tumour metastasis [11]. Kogo et al. [12] found that IncRNA HOTAIR plays a critical role in stage IV colorectal cancer, confirming that the expression of IncRNA HOTAIR in colorectal cancer is higher than that in adjacent tissues. Yang et al. [13] found that the increased expression of IncRNA HOTAIR is associated with tumour recurrence 
following liver transplantation in HCC patients, which can be used as an independent prognostic factor. In the study of drug resistance, the sensitivity of tumour cells to cisplatin and doxorubicin is correlated with the expression level of IncRNA HOTAIR $[14,15]$, indicating that InCRNA HOTAIR not only serve as a biomarker for tumour prognosis but also as a potential therapeutic target.

From the results of this study, the expression of IncRNA HOTAIR is high in patients with advanced HCC, and this high expression of IncRNA HOTAIR is not correlated with clinicopathological characteristics, and the expression level of IncRNA HOTAIR in tumour tissue and peripheral blood is correlated $(r=0.638, p<0.001)$, which are consistent with previous studies, indicating that IncRNA HOTAIR also plays an important role in HCC. In the analysis of survival, patients with low expression of IncRNA HOTAIR in tumour tissue and peripheral blood are more likely to benefit from sunitinib therapy, obtaining longer OS and PFS. In addition, COX regression analysis showed that IncRNA HOTAIR was an independent prognostic factor for sunitinib in treating advanced HCC.

Collectively, we demonstrate that IncRNA HOTAIR is highly expressed in tissues and peripheral blood of patients with advanced HCC, and IncRNA HOTAIR can be used as an independent prognostic factor for sunitinib in treating advanced HCC. However, the exact conclusions require a larger sample size to be verified, and how IncRNA HOTAIR affects the efficacy of sunitinib remains to be further studied. In summary, this study provides a new idea for the individualized therapy of sunitinib in clinical practice.

In conclusion, IncRNA HOTAIR is highly expressed in tissues and peripheral blood of patients with advanced HCC, and IncRNA HOTAIR can be used as an independent prognostic factor for sunitinib in treating advanced HCC.

\section{Acknowledgments}

Thanks to The Second Affiliated Hospital of Jiaxing University for providing experimental sites and theoretical support, thanks to the laboratory workers in the central laboratory.

\section{Conflict of interest}

The authors declare no conflict of interest.

\section{Reference}

1. Sakurai Y, Kubota N, Takamoto I, et al. Role of insulin receptor substrates in the progression of hepatocellular carcinoma. Sci Rep 2017; 7: 5387.

2. Hammond JS, Franko J, Holloway SE, et al. Gemcitabine transcatheter arterial chemoembolization for unresect- able hepatocellular carcinoma. Hepatogastroenterology 2014; 61: 1339-43.

3. Ippolito D, Fior D, Bonaffini PA, et al. Quantitative evaluation of CT-perfusion map as indicator of tumor response to transarterial chemoembolization and radiofrequency ablation in HCC patients. Eur J Radiol 2014; 83: 1665-71.

4. Simoneau E, Vauthey JN. Progression of colorectal cancer liver metastasis after chemotherapy: a new test of time? Ann Surg Oncol 2018; 25: 1469-70.

5. Ruiz-Morales JM, Swierkowski M, Wells JC, et al. Firstline sunitinib versus pazopanib in metastatic renal cell carcinoma: results from the International Metastatic Renal Cell Carcinoma Database Consortium. Eur J Cancer 2016; 65: 102-8.

6. Oudard S, Geoffrois L, Guillot A, et al. Clinical activity of sunitinib rechallenge in metastatic renal cell carcinoma-Results of the REchallenge with SUnitinib in MEtastatic RCC (RESUME) Study. Eur J Cancer 2016; 62: 28-35.

7. Botti G, Marra L, Malzone MG, et al. LncRNA HOTAIR as prognostic circulating marker and potential therapeutic target in patients with tumor diseases. Current Drug Targets 2016; 18: 27-34.

8. Poelstra K, Prakash J, Beljaars L. Drug targeting to the diseased liver. J Control Release 2012; 161: 188-97.

9. Motzer RJ, Hutson TE, Tomczak P, et al. Sunitinib versus interferon alfa in metastatic renal-cell carcinoma. N Engl J Med 2007; 356: 115-24.

10. Koeberle D, Montemurro M, Samaras P, et al. Continuous sunitinib treatment in patients with advanced hepatocellular carcinoma: a Swiss Group for Clinical Cancer Research (SAKK) and Swiss Association for the Study of the Liver (SASL) Multicenter Phase II Trial (SAKK 77/06). Oncologist 2010; 15: 285-92.

11. Gupta RA, Shah N, Wang KC, et al. Long non-coding RNA HOTAIR reprograms chromatin state to promote cancer metastasis. Nature 2010; 464: 1071-6.

12. Kogo R, Shimamura T, Mimori K, et al. Long noncoding rna hotair regulates polycomb-dependent chromatin modification and is associated with poor prognosis in colorectal cancers. Cancer Res 2011; 71: 6320-6.

13. Yang Z, Zhou L, Wu LM, et al. Overexpression of long non-coding RNA HOTAIR predicts tumor recurrence in hepatocellular carcinoma patients following liver transplantation. Ann Surg Oncol 2011; 18: 1243-50.

14. Liu MY, Li XQ, Gao TH, et al. Elevated HOTAIR expression associated with cisplatin resistance in non-small cell lung cancer patients. J Thorac Dis 2016; 8: 3314-32.

15. Banas T, Pitynski K, Okon K, et al. Immunoexpression of DNA fragmentation factor 40, DNA fragmentation factor 45 , and B-cell lymphoma 2 protein in normal human endometrium and uterine myometrium depends on menstrual cycle phase and menopausal status. Arch Med Sci 2017; 14: 1254-62. 